\title{
Deformation and damage characteristics of ball bearings under blast loading
}

\author{
Ruixuan $\mathrm{Qi}^{1}$, Genevieve $S$ Langdon ${ }^{1,2}$, Trevor $\mathrm{J} \mathrm{Cloete}^{1 *}$ and Steeve Chung Kim Yuen ${ }^{1}$ \\ ${ }^{1}$ Blast and Impact Survivability Research Unit (BISRU), Department of Mechanical Engineering, \\ University of Cape Town, Rondebosch, 7700, South Africa \\ ${ }^{2}$ Department of Civil and Structural Engineering, University of Sheffield, Sheffield, S13JD, United \\ Kingdom
}

\begin{abstract}
This paper presents the unique failure characteristics, such as fragmentation, internal cracks, general deformation and pitting, observed on a SS420C ball bearing from direct blast loading using a cylindrical PE-4 explosive. Axisymmetric simulations were performed to gain insights of the failure mechanisms. While additional work is needed to fully understand all characteristic found, valuable findings have been presented to explain some of the failures.
\end{abstract}

\section{Introduction}

Improvised explosive devices (IEDs) cause thousands of deaths and injuries each year [1]. IEDs are particularly lethal when embedded with solid objects such as ball bearings or nails. Understanding the behaviour of blast-driven ball bearings embedded in explosive charges will aid in the development of blast protection from IEDs. Previous work by the authors [2] has focussed on the flight characteristics of a single ball bearing driven by the detonation of plastic explosive. This proved to be a useful experimental arrangement for gaining fundamental insights into the momentum transfer and flight of a solid insert from a simplified IED. This paper builds on previous work by examining the effect of the detonation and blast on the damage incurred by the ball bearing itself.

\section{Experimentation}

\subsection{Blast tests}

Blast experiments were performed to emulate a simplified IED. As shown in Fig. 1, a $5 \mathrm{~mm}$ diameter SS420-c spherical ball bearing was half embedded in a rear-detonated cylindrical charge. PE4 explosive charge masses ranging from $2.2 \mathrm{~g}$ to $27 \mathrm{~g}$ were used to conduct a series of small-scale blast tests. The ball bearings were allowed to impact an aluminium witness plate. The impact crater depth was used to infer the impact velocities of the ball bearing by comparing against results obtained from a separate series of impact tests using a light gas

\footnotetext{
*trevor.cloete@uct.ac.za
} 
gun. The witness plate was supported by a Hopkinson Pressure Bar (HPB) of equal diameter. The HPB was used to infer the in-flight velocity of the ball bearing. The detailed experimental arrangement and flight analysis of the ball bearings are presented in refs $[2,3]$.

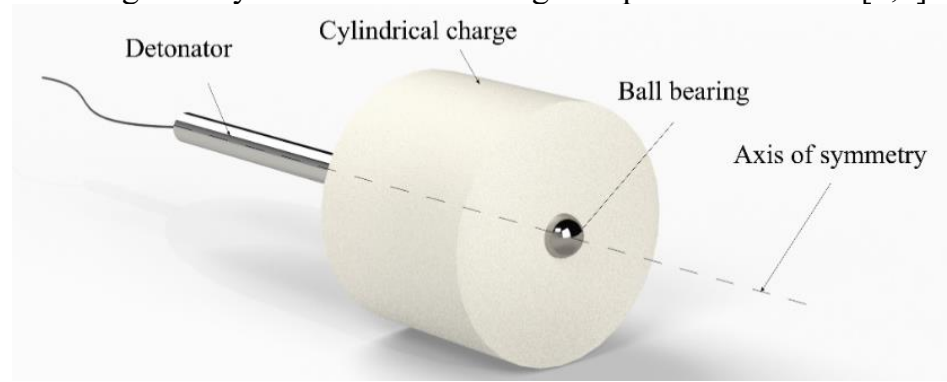

Fig. 1 Schematic showing a rear-detonated PE-4 explosive charge with a ball bearing embedded in the front surface.

\subsection{Gas gun tests}

Gas gun tests were performed as comparisons to isolate the effect of blasting from the impact on ball bearings. The experiments were carried out using a custom-built two-stage gas-gun using the same witness plate material and ball bearings. Impact experiments were able to achieve the velocities inferred during the blast tests, up to $570 \mathrm{~m} / \mathrm{s}$.

\subsection{Specimens}

The mean mass of the ball bearings was $505 \mathrm{mg}$ with a standard deviation of $0.12 \%$ after taking 50 samples. The sphericity of the ball bearings was found to be within $1 \mu \mathrm{m}$. Two ball bearings were sectioned and Vickers hardness tests were conducted on two cross-section samples (using loads of $20 \mathrm{kgf}$ and $30 \mathrm{kgf}$ ). It was determined that the ball bearings had a hardness of 628-648 (HV10), suggesting an ultimate tensile strength range 2098-2173 MPa using DIN 50150 [4]. The yield strength was estimated to be $1685 \pm 100 \mathrm{MPa}$ using Pavlina's correlation [5] for martensitic metals. The ball bearing does not appear to be case hardened as the etched bearing cross-sections showed a consistent microstructure.

\subsection{Computational simulations}

Two-dimensional axisymmetric simulations were performed using Ansys Autodyn 19.0. A schematic, shown in Fig. 2, defines the positioning of parts, gauges and boundary conditions. The Equation of States and mesh sizes used for the air and PE4 are identical to that presented previously [2]. The previous model [2] has now been improved upon, to examine the damage evolution in the ball bearing. The Johnson-Cook strength parameters and maximum stress failure criteria used for the SS420 is presented in Table 1.

Table 1 Material models and parameters used in the numerical simulation.

\begin{tabular}{|c|c|c|c|c|c|c|}
\hline \multicolumn{5}{|c|}{ Johnson-Cook Strength Model } & \multicolumn{2}{|c|}{ Principle stress damage model } \\
\hline $\begin{array}{c}\text { Shear } \\
\text { Modulus } \\
(\mathrm{GPa})\end{array}$ & $\begin{array}{l}\text { Yield } \\
\text { stress } \\
\text { (Mpa) }\end{array}$ & $\begin{array}{c}\text { Hardening } \\
\text { Constant } \\
(\mathrm{Mpa}) \\
\end{array}$ & $\begin{array}{l}\text { Hardening } \\
\text { Exponent }\end{array}$ & $\begin{array}{l}\text { Strain rate } \\
\text { constant }\end{array}$ & $\begin{array}{c}\text { Tensile } \\
\text { failure stress } \\
(\mathrm{GPa})\end{array}$ & $\begin{array}{c}\text { Shear failure } \\
\text { stress } \\
\text { (Mpa) }\end{array}$ \\
\hline 80 & 2173 & 1785 & 0.6 & 0.023 & 21 & 390 \\
\hline
\end{tabular}




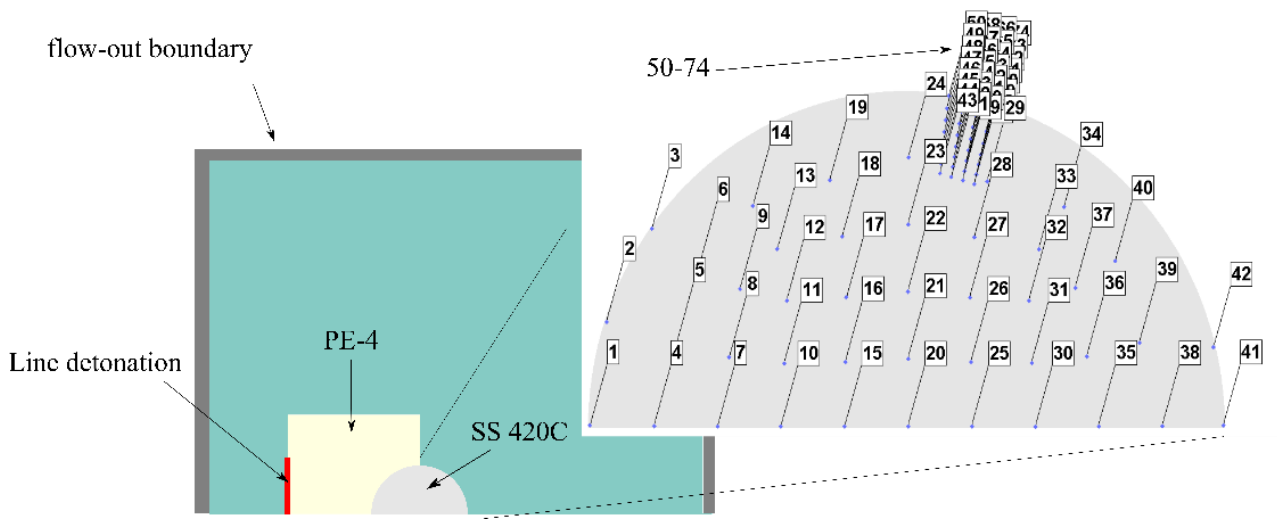

Fig. 2 Schematics of the simulations (not-to-scale) showing (a) the IED experimental arrangement, (b) a zoomed in section of the ball bearing defining the location of the gauges.

\section{Results and discussion}

\subsection{Typical ball bearing blast damage}

Ball bearings were recovered after the blast tests. However, due to the small size of the ball bearings, it was not always possible to identify them immediately after each blast test among the explosive residue. In total, 16 ball bearings were recovered. Two were traced to their experiment. The recovered bearings, shown in Fig. 3 exhibited $2.8 \%$ average mass reduction.

For illustration, Face A was regarded as the top half of the hemisphere and Face B being the lower half.

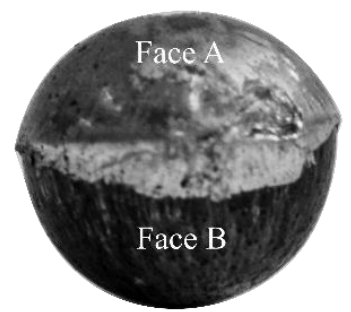

a)

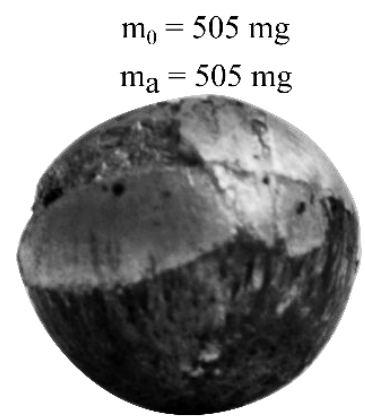

d)

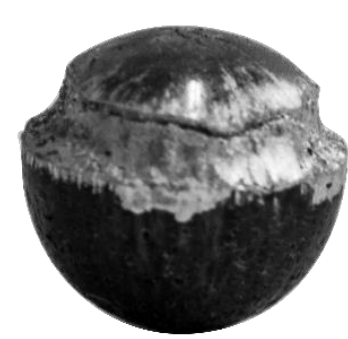

b) $\quad 5.13-18-0.7$

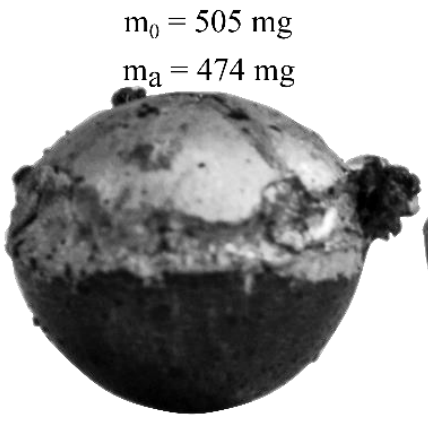

f) $\mathrm{m}_{\mathrm{a}}=488 \mathrm{mg}$

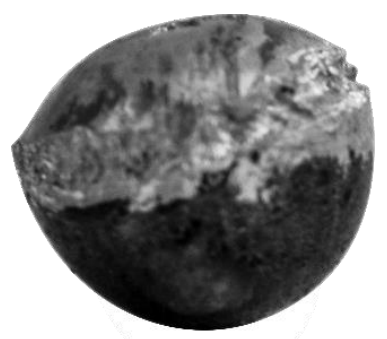

c) $\mathrm{m}_{\mathrm{a}}=487 \mathrm{mg}$

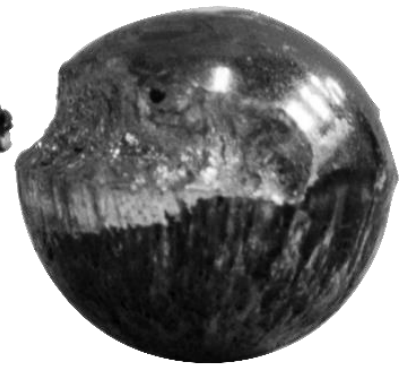

g) $\mathrm{m}_{\mathrm{a}}=470 \mathrm{~g}$

Fig. 3 Collection of photographs showing the damaged ball bearing from blasting, arranged in charge mass of the experiment. 
Consistent failure features were observed across the recovered ball bearing, such as the general deformation in geometry and distribution of localised damage. These features can be summarised as an overall change in geometry from spherical to ellipsoidal (particularly in Fig. 3, a, c and f) with the maximum circumference around the equator. In general, Face B appears to be more spherical than Face A. Face A appeared to be shinier appearance, while Face B was duller and darker. Fragmentation occurred at the equator but was more concentrated on Face A. The bearings exhibited a "fold" extruded around the equator, with streak marks radiating from the poles of the bearing. This was more visible on Face B. Internal cracks were also found after cross-sectioning the blasted samples.

\subsection{Damage due to impact}

The comparison between ball bearings before testing (unused), after gas gun, and blast tests are shown in Fig. 4. The ball bearing from gas gun impact tests were indistinguishable from an unused ball bearing. The unique features described in Section 3.1 are therefore likely to be a result of blasting alone.

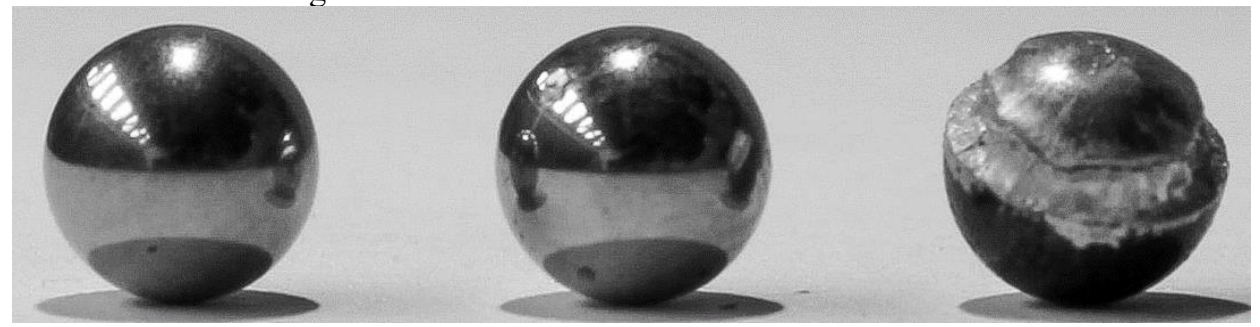

Fig. 4 Comparison between an unused ball bearing (left), ball bearing after a $570 \mathrm{~m} / \mathrm{s}$ gas gun tests (centre) and a ball bearing after blasting (right).

\subsection{Damage from the blast: insight from simulations}

While Face A of the bearing generally sustained more damage (fragmentation and deformation), the numerical result indicate that Face B was the contacting hemisphere with the explosive. In Fig. 5, a $5.13 \mathrm{~g}$ detonation was simulated and the deformed bearing shape was compared to its experimental counterpart. Asymmetrical deformation between Face A and B was observed both numerically and experimentally. The numerical result was most similar to the observed behaviour if Face B was interpreted as the explosive contacting side. The simulation predicted that the explosive facing hemisphere would remain spherical while the opposite side would flatten. As shown in Fig. 5, internal cracking was present on the cross-section of the blasted sample and also predicted in the numerical simulation. The location of the simulated internal cracks matched those found experimentally. Lastly, while the model did not indicate fragmentation around the equator, the maximum effective plastic strain was shown to be in a similar region as the actual fragmented location. The lack of fragmentation in the model could be due to the limited capability of the failure model used in the simulation.

Simulations showed that internal cracks (Fig. 5) formed from spalling. The location of the cracking was a result of the geometry of the ball bearing, as the hydrostatic pressure waves reflected from the curved free surface of Face A and caused an internal hydrostatic tensile pressure state that coincided at the crack location. The hydrostatic pressure history for gauges in hemisphere A and B of the ball bearing are shown in Fig. 6. The location of the gauges is shown in Fig. 2. In general, gauges 4 and 10 (Face B) had similar pressure histories. 
The initial compressive stress wave can be observed in Fig. 6 to have propagated from gauges 4 and 10 with similar magnitude (approx. $32 \mathrm{GPa}$ ). This was increased to approximately $36 \mathrm{GPa}$ in Face A (gauges 25 to 35 ) as there was a focusing effect due to the curvature of Face B. This strengthened compressive wave was reflected as a tensile wave at $2.2 \mu \mathrm{s}$ and reached a maximum at $2.3 \mu \mathrm{s}$ which caused the internal cracking. At $2.3 \mu \mathrm{s}$, material at gauge 35 had failed, resulting in a sharp decline in pressure.
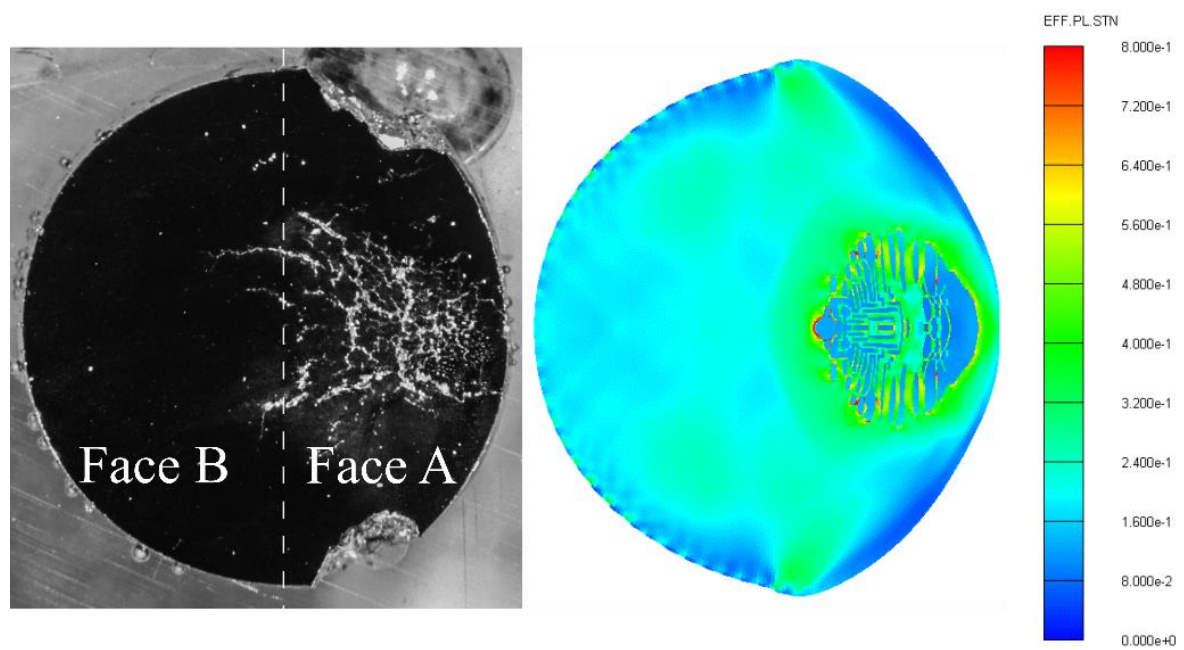

Fig. 5 Comparison of a sectioned ball bearing from a $5.13 \mathrm{~g}$ detonation (left) and the effective plastic strain contour from an equivalent simulation at $2.5 \mu \mathrm{s}$ after detonation (right).

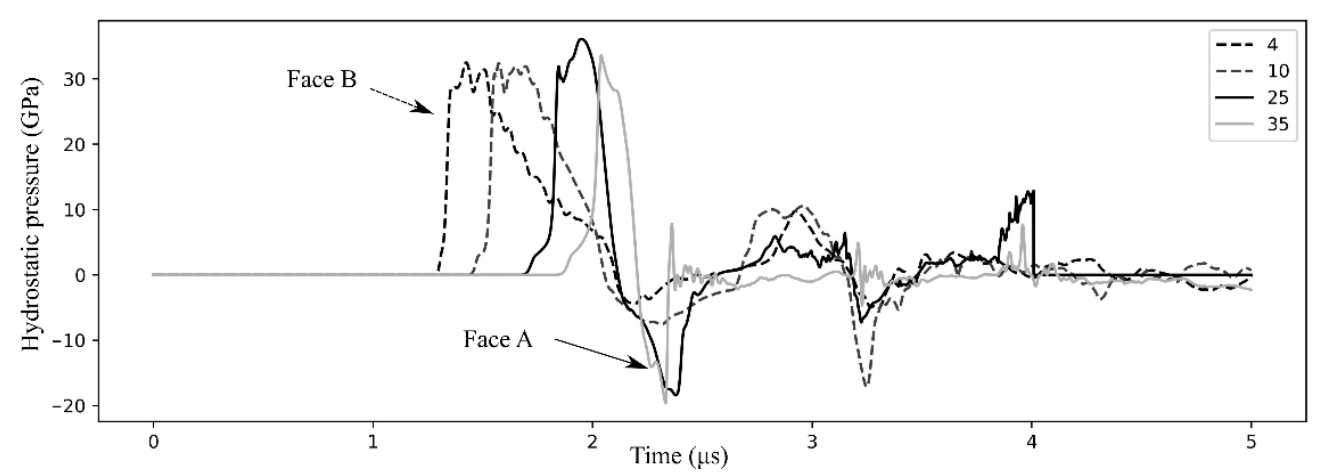

Fig. 6 Simulated hydrostatic pressure history graph of Face A (solid) and Face B (dotted).

Positive pressure indicates compression.

\subsection{Pitting}

The magnified photographs of the ball bearing from the detonation of a $5.13 \mathrm{~g}$ of PE4 are shown in Fig. 7. The dullness on Face B was due to a roughened surface with extensive "pitting" (shown in Fig. 7b). The cause of pitting was unclear. For example, the pits did not appear to be micro impact crater due to the absence of distinguishing features, such as rims, and the exact causes would require future investigation. 


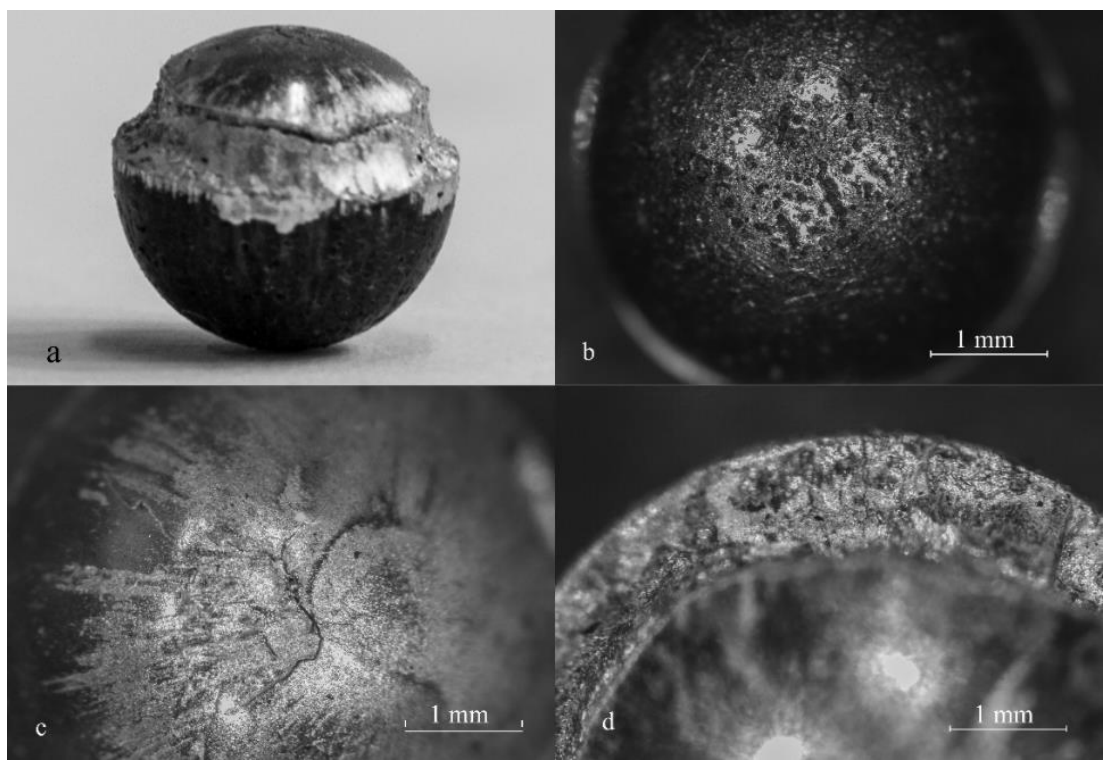

Fig. 7 Collection of photographs showing, a) damaged ball bearing after a 5.13 g detonation, b) magnified top view of Face B of the bearing in a, c) magnified top view of the Face A, d) magnified view of the fragmented section.

\section{Conclusions}

A series of blast experiments were performed to investigate the damage characteristics of SS $420 \mathrm{C}$ ball bearings from explosives. Unique damage features were found across all the recovered specimens that were as a result of the blasting.

Numerical simulations were performed and compared to the result of a $5.13 \mathrm{~g}$ PE-4 detonation. Many features, such as the overall deformations and internal cracking were predicted by a model. The numerical model was used to confirm the direction of blasting relative to the ball bearing and to explain the internal cracking found.

Additional features including pitting, surface cracks, fragmentation and streak marks were observed in the blasted ball bearings. The failure mechanism for each of these features will require further investigation.

\section{References}

[1] I. Overton, J. Dathan, C. Winter, J. Whittaker et al. Improvised explosive device monitor 2017, Action On Armed Violence. AOAV Tech Rep, (2017)

[2] R. Qi, G.S. Langdon, T.J. Cloete, S. Chung Kim Yuen, Behaviour of a blast-driven ball bearing embedded in rear detonated cylindrical explosive, Int J Impact Eng, 146, 103698, (2020)

[3] R. Qi, The influence of cylindrical charge geometry on the velocity of blast-driven projectiles in one dimension, University of Cape Town, MSc dissertation, (2020)

[4] Testing of Steel and Cast Steel; Conversion Table for Vickers Hardness, Brinell Hardness, Rockwell Hardness and Tensile Strength, publishing DIN, (1976)

[5] Pavlina E.J. , Van Tyne C.J., Correlation of yield strength and tensile strength with hardness for steels. J Mater Engng Performance, 17, 6, (2008) 